\title{
Effect of UV Irradiation on The Structure and Optical Properties of PVA/Cucl 2
}

\author{
T. Fahmy ${ }^{1,2^{\star}}$, A. Sarhan ${ }^{2}$, I. A. Elsayed ${ }^{1,3}$, M. T. Ahmed ${ }^{2}$ \\ ${ }^{1}$ Physics Dept., College of Science and Humanity, Prince Sattam bin Abdulaziz University, 11942 Alkharj, \\ Kingdom of Saudi Arabia. \\ ${ }^{2}$ Polymer Research Group, Physics Dept., Faculty of Science, Mansoura University, 35516 Mansoura, Egypt. \\ ${ }^{3)}$ Physics Dept., Faculty of Science, Damietta University, New Damietta, Egypt. \\ tfahmy_5@yahoo.com,moustf_1@yahoo.com
}

\section{ABSTRACT}

The morphology and optical properties of doped PVA with Copper $\mathrm{Chloride}, \mathrm{CuCl}_{2}$ have been investigated. The morphology of doped samples has been examined using both atomic force microscope (AFM) and scanning electron microscope (SEM) to investigate the effect of $\mathrm{CuCl}_{2}$ on the structure of PVA. X-ray diffraction showed that the crystallinity of PVA is increased with increasing $\mathrm{CuCl}_{2}$ ratio. In addition, FTIR spectra showed that, some absorbance bands such as bands of $\mathrm{OH}$ groups have been affected due to $\mathrm{CuCl}_{2}$ ratio and UV irradiation. On the other hand, the effect of $\mathrm{CuCl}_{2}$ ratio and UV irradiation on UV spectra of all samples has been carried out in the range from 200 to $800 \mathrm{~nm}$. It is observed that, PVA is characterized by two absorbance bands at 278 and $313 \mathrm{~nm}$. The values of absorbance edge, Urbach energy and the direct energy gap of all samples have been calculated.

Keywords: Morphology, AFM, x-ray diffraction, Optical properties, absorbance edge, Urbach energy.

Language: English

Date of Publication: 31-05-2018

DOI: 10.24297/jap.v14i2.7358

ISSN: 2347-3487

Volume: 14 Issue: 2

Journal: Journal of Advances in Physics

Website: https://cirworld.com

This work is licensed under a Creative Commons Attribution 4.0 International License. 


\section{Introduction}

Poly (vinyl alcohol) (PVA) is considered as one of the important polymers and can be obtained in different forms such as, powder, film and fiber. PVA is non-toxic, water soluble polymer with a broad range of applications in many fields, such as biomedicine, pharmacy, biosensors, solid-state batteries and solid-state electrochromic displays [1-4]. The wide applications of PVA are due to its excellent chemical and physical properties.

Currently, composites have been synthesized using different polymers and dopant materials such as metals, oxides and inorganic salts [5-7]. As already well known, PVA has carbon chain with hydroxyl groups attached that can be a source of hydrogen bonding which assists the formation of polymer nano-composite. The incorporation of the dopants materials into polar organic polymers will produce pronounced changes in various properties of polymers to modify and improve its properties $[8,9]$.

The investigation of optical spectroscopy gives more information about the band structure and the optical energy gap of the materials. The main purpose of this work is to investigate the effect of UV irradiation on the structure and optical properties of pure PVA and the composite of $\mathrm{PVA} / \mathrm{CuCl}_{2}$.

\section{Experimental Work}

PVA $\left(\mathrm{M}_{\mathrm{w}}=72,000\right)$ is purchased from Merck, (Germany) and Copper Chloride $\left(\mathrm{CuCl}_{2}\right)$ is purchased from $\mathrm{BDH}$ Chemicals Ltd, Poole, (England). Doped PVA samples with a different ratio of Copper Chloride $\left(\mathrm{CuCl}_{2}\right)$ are prepared by dissolving them in distilled water at $\mathrm{T}=333 \mathrm{~K}$ for $10 \mathrm{hr}$. The solution is continuously stirred using a hot plate with a magnetic stirrer for $6 \mathrm{hr}$ to ensure a homogeneous mixture. The solution is then cast in a petri dish and dried in an oven at $\mathrm{T}=333 \mathrm{~K}$ for $24 \mathrm{hr}$.

X-ray diffraction pattern of all samples is carried out using Rigaku Ultima IV diffractometer with $\mathrm{Cu}$ $\mathrm{K} \cdot$ radiation $(\cdot=1.5418 \AA$ ) at $40 \mathrm{kV}$. Atomic force microscope (AFM) is investigated using Bruker Dimension Icon system with Scan Asys mode (tapping). Scanning electron microscope (SEM) is investigated using FEI Quanta 250 FEG. FT-IR is investigated in the range from 400 to $4000 \mathrm{~cm}^{-1}$ using FT-IR spectroscopy, Mattson, UK. UV spectra are carried out in the range from 200 to $800 \mathrm{~nm}$ by UV/VIS Unicom, Mattson, UK.

\section{Results and Discussion}

\section{1: Atomic Force Microscopy (AFM)}

(a)

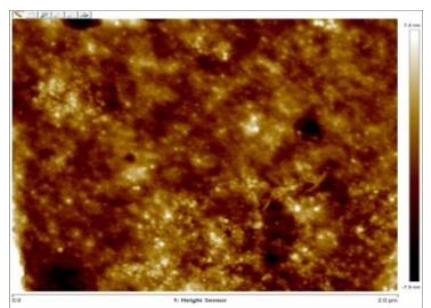

(b)

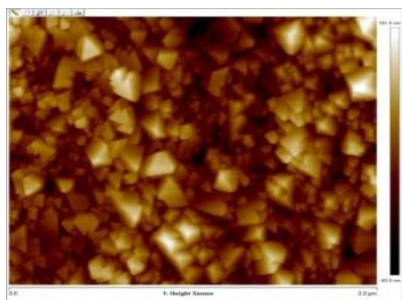

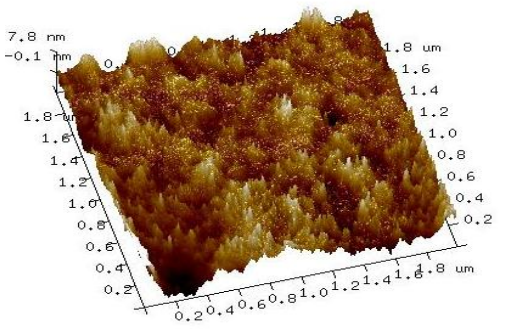

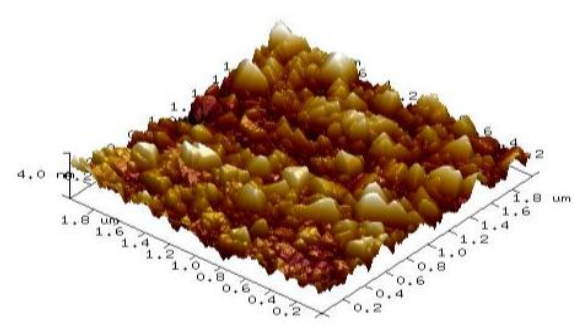


(c)

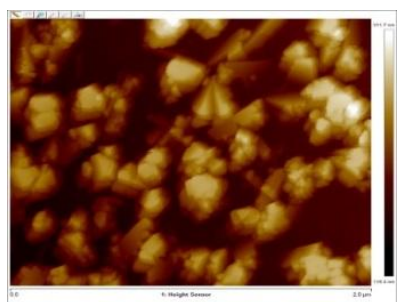

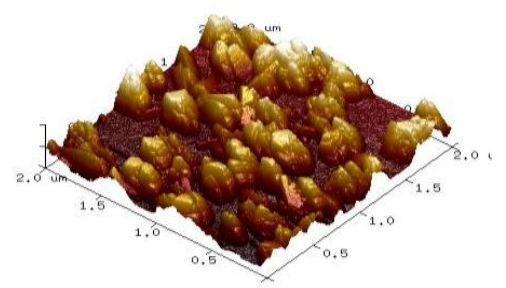

Fig. 1: AFM images of: a) Pure PVA, b) $80 w t \% ~ P V A / 20 w t \% ~ \mathrm{CuCl}_{2}$ and c) irradiated $80 w t \%$ $\mathrm{PVA} / 20 \mathrm{wt} \% \mathrm{CuCl}_{2}$ doped sample.

The surface roughness of doped PVA samples is investigated using AFM. Fig. 1 shows AFM-3D height mode of $\mathrm{PVA} / \mathrm{CuCl}_{2}$ composite film surface with different doping ratio of $\mathrm{CuCl}_{2}$. It is found that, $\mathrm{PVA} / \mathrm{CuCl}_{2}$ films are characterized by different surface colors. The ratio between bright domains area to darker domains area is also different, revealing that surface roughness of the polymer composite film is changed with the increase of $\mathrm{CuCl}_{2}$ content $[10,11]$. This behavior indicates that the variation of surface roughness of polymer composite films can be attributed to the dopant materials of $\mathrm{CuCl}_{2}$. Different parameters such as a variation of average roughness, RMS of surface roughness and the average height of doped PVA samples with different doping concentrations are estimated from AFM data and listed in Table 1. It is observed that, the values of these parameters are increased for composite samples in comparison with pure PVA. This could be attributed to more nucleation sites produced by $\mathrm{CuCl}_{2}$. The increasing of RMS roughness of highly doped sample could be attributed to agglomeration of $\mathrm{CuCl}_{2}$.

Table 1. The values of average roughness $\left(R_{a}\right), R M S$ roughness $\left(R_{q}\right)$ and average height $\left(R_{\max }\right)$ of pure PVA and composite samples.

\begin{tabular}{cccc}
\hline Material & $\begin{array}{c}\text { Average surface } \\
\text { roughness } \mathrm{R}_{\mathrm{a}} \\
(\mathrm{nm})\end{array}$ & $\begin{array}{c}\text { RMS surface } \\
\text { roughness } \\
\mathrm{R}_{\mathrm{q}}(\mathrm{nm})\end{array}$ & $\begin{array}{c}\text { Average height } \\
(\mathrm{nm})\end{array}$ \\
\hline Pure PVA & 2.91 & 1.85 & 51.4 \\
20wt\% CuCl$/ 80 \mathrm{wt} \%$ PVA & 27.8 & 21.9 & 202 \\
20wt\% CuCl$/ 80 \mathrm{wt} \%$ & 31.1 & 26.8 & 165 \\
PVA_irradiated & & &
\end{tabular}

\section{2: Scanning Electron Microscope (SEM)}

(a)

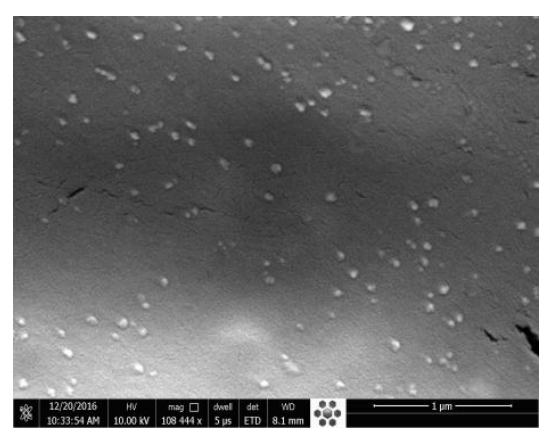

(b)

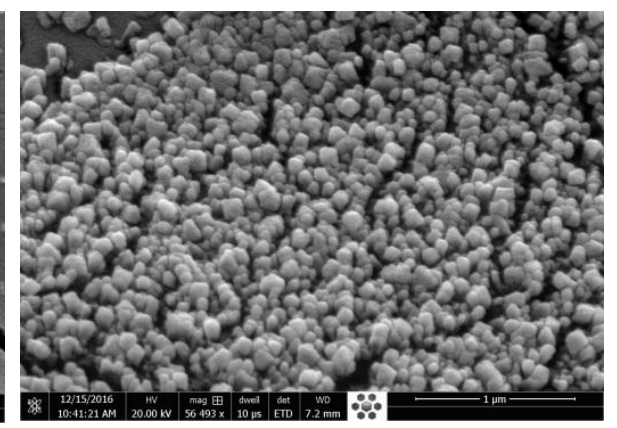

(c)

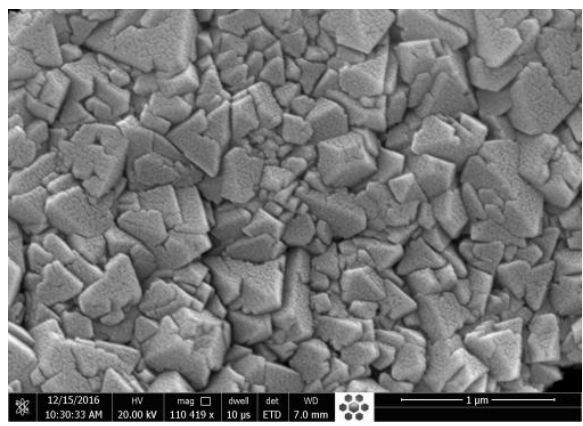

Fig.2: SEM images of a) 95 wt\% PVA/5wt $\% \mathrm{CuCl}_{2}$, b) $80 w t \% \mathrm{PVA} / 20 w t \% \mathrm{CuCl}_{2}$ and c) irradiated $80 w t \%$ $\mathrm{PVA} / 20 \mathrm{wt} \% \mathrm{CuCl}_{2}$ doped sample. 
The morphology of doped PVA samples is investigated using scanning electron microscope (SEM), as shown in Fig. 2. The introducing of $\mathrm{CuCl}_{2}$ into PVA changed the morphology of the PVA film. It can be seen from Fig. $2 \mathrm{a}$, there is a little density of $\mathrm{CuCl}_{2}$ distribution. On the other hand, with increasing $\mathrm{CuCl}_{2}$ ratio, the surface morphology of composite films became uneven and formed an aggregation and dispersed in the PVA matrix, as observed in Fig. 2(b\&c). The change of microstructure of PVA could be related to forming intermolecular hydrogen bonds [12] due to the interaction between PVA segments and $\mathrm{CuCl}_{2}$.

\section{3: X-ray diffraction analysis (XRD)}

X-ray diffraction pattern of pure PVA and PVA/CuCl 2 doped samples has been depicted in Fig. 3a. The main peak at $2 \theta=19.93^{\circ}$ is observed for pure PVA characterizing the PVA crystalline phase [13], whereas, XRD pattern of pure $\mathrm{CuCl}_{2}$ is characterized by many sharp peaks at $20.78^{\circ}, 28.52^{\circ}, 32.48^{\circ}, 35.62^{\circ}$ and $40.16^{\circ}$. On the other hand, as the $\mathrm{CuCl}_{2}$ ratio is increased in $\mathrm{PVA} / \mathrm{CuCl}_{2}$ doped samples, new sharp diffraction peaks are observed at $10.96^{\circ}, 17.72^{\circ}, 32.48^{\circ}$ and $39.75^{\circ}$, indicating the growth of $\mathrm{CuCl}_{2}$ crystallites in PVA matrix [14]. The program Dicvol104 is used to determine unit cell parameter [15]. The best solution to index the welldefined peaks (9) in the range $3^{0}-60^{\circ}$ gives the triclinic cell, with $a=6.8967 \AA, b=6.2212 \AA, c=8.5418 \AA$, $\cdot=$ $78.687^{\circ}, \cdot=97.435^{\circ} \gamma=93.618^{\circ}$ and volume of $356.08 \AA$.
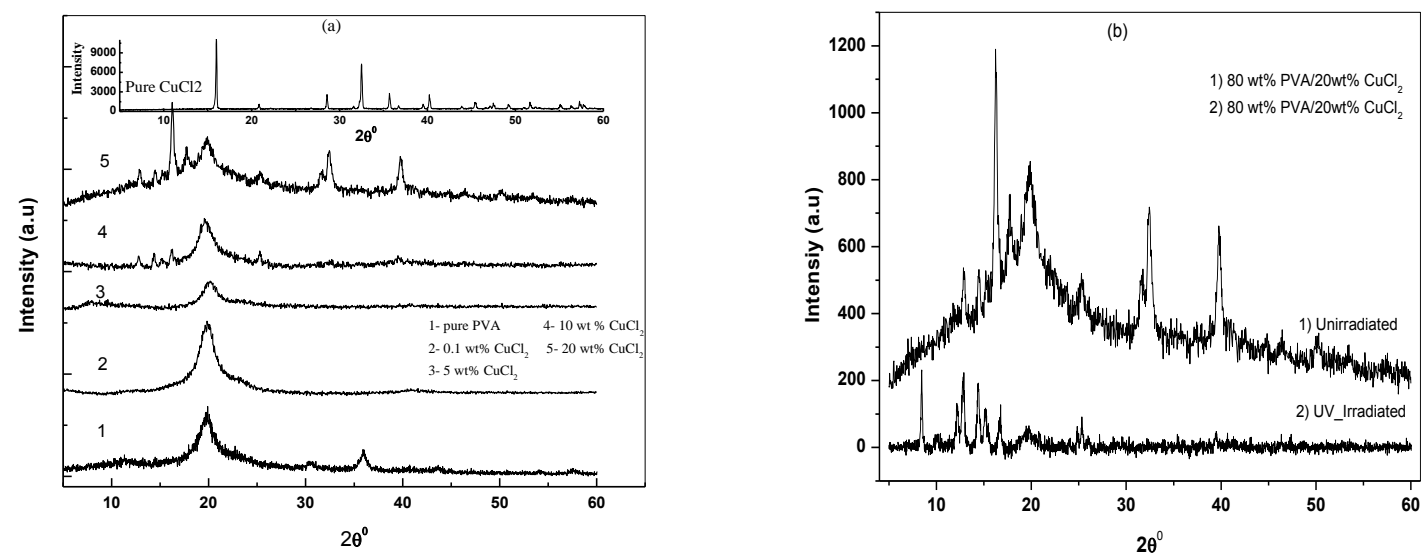

Fig. 3: XRD of: a) pure PVA and PVA-CuCl 2 doped samples and b) unirradiated and irradiated doped sample.

The effect of UV-irradiation is examined on XRD pattern of the highly doped sample as shown in Fig. $3 b$. It is observed that the intensity of diffraction peaks is decreased and new peaks are raised while others are disappeared. This behavior could be attributed to the increase of the crosslinking induced in the polymer matrix which implies a presence of a strain on the crystals as a result of the formation of a three-dimensional network of chains.

\section{4: FT-IR Spectroscopy}

As already well known, FT-IR is used to investigate the complexation and interactions in polymeric materials. Fig. 4a displays FT-IR spectra of $\mathrm{PVA} / \mathrm{CuCl}_{2}$ composite samples in the wavenumber region from 500 to $4000 \mathrm{~cm}^{-1}$. It is observed that FT-IR spectrum of pure PVA is characterized by many absorption bands, such as, $848 \mathrm{~cm}^{-1}$ is assigned to unsaturated $\mathrm{CH}_{2}$ stretching of PVA, the bands at 1334,1250 and $1092 \mathrm{~cm}^{-1}$ are due to the interaction between $\mathrm{O}-\mathrm{H}$ bending and $\mathrm{C}-\mathrm{O}$ stretching, the band at $1429 \mathrm{~cm}^{-1}$ is assigned to $-\mathrm{COO}$ stretching vibrations. In addition, IR band at $1718 \mathrm{~cm}^{-1}$ is assigned to $C=O$ stretching and bands in the range from 3237 to $3400 \mathrm{~cm}^{-1}$ are assigned to $(\mathrm{OH})$ intermolecular hydrogen bonding. On doping with $\mathrm{CuCl}_{2}$, the structure of some bands of pure PVA such as, 3298, 3237, 2938, 1718, 1429 and $1092 \mathrm{~cm}^{-1}$, have been shifted towards $3264,3216,1708,1418$ and $1079 \mathrm{~cm}^{-1}$, as shown in Fig 4 a. On the other hand, doping with $\mathrm{CuCl}_{2}$ 
leads to an increase in the absorbance intensity of the band at $1092 \mathrm{~cm}^{-1}$, which is considered as a measure of the crystallinity degree of PVA, as shown in Fig. 4b [16].
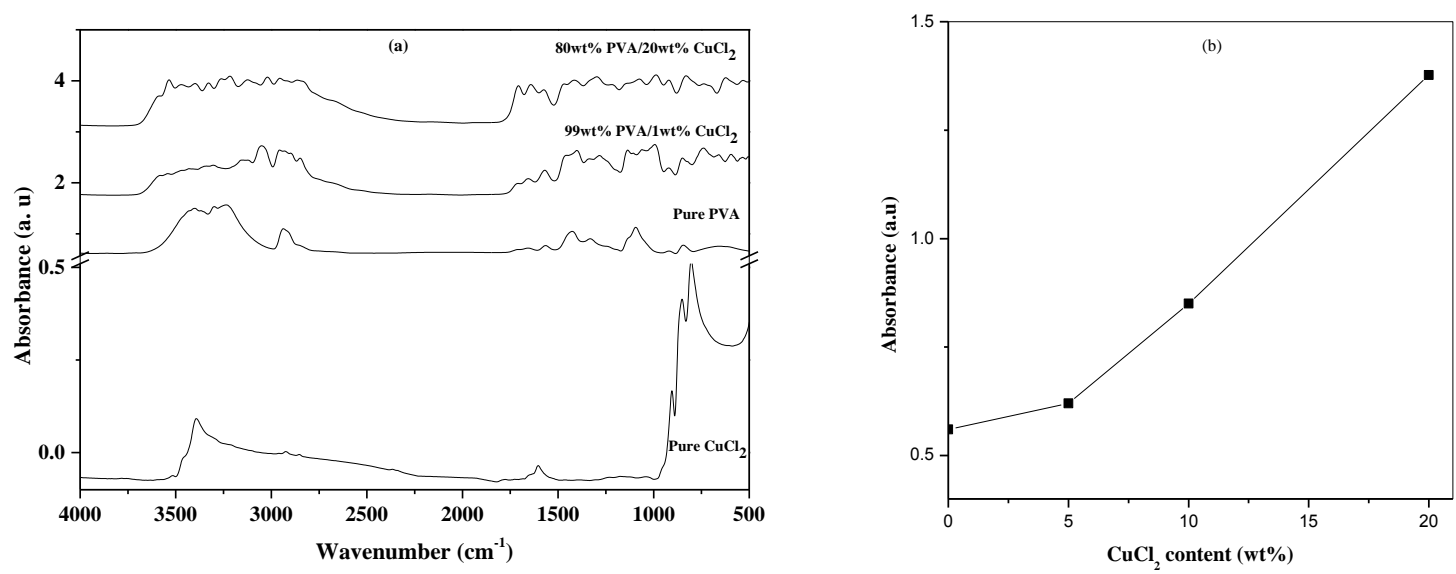

Fig. 4: FT-IR of: a) PVA/CuCl 2 doped samples, b) The absorbance intensity of $1090 \mathrm{~cm}^{-1}$ band versus $\mathrm{CuCl}_{2}$ content, c) The unirradiated and irradiated $90 \mathrm{wt} \% \mathrm{PVA} / 10 \mathrm{wt} \% \mathrm{CuCl}_{2}$ and d) The absorbance intensity of $3365 \mathrm{~cm}^{-1}$ band versus irradiation time.
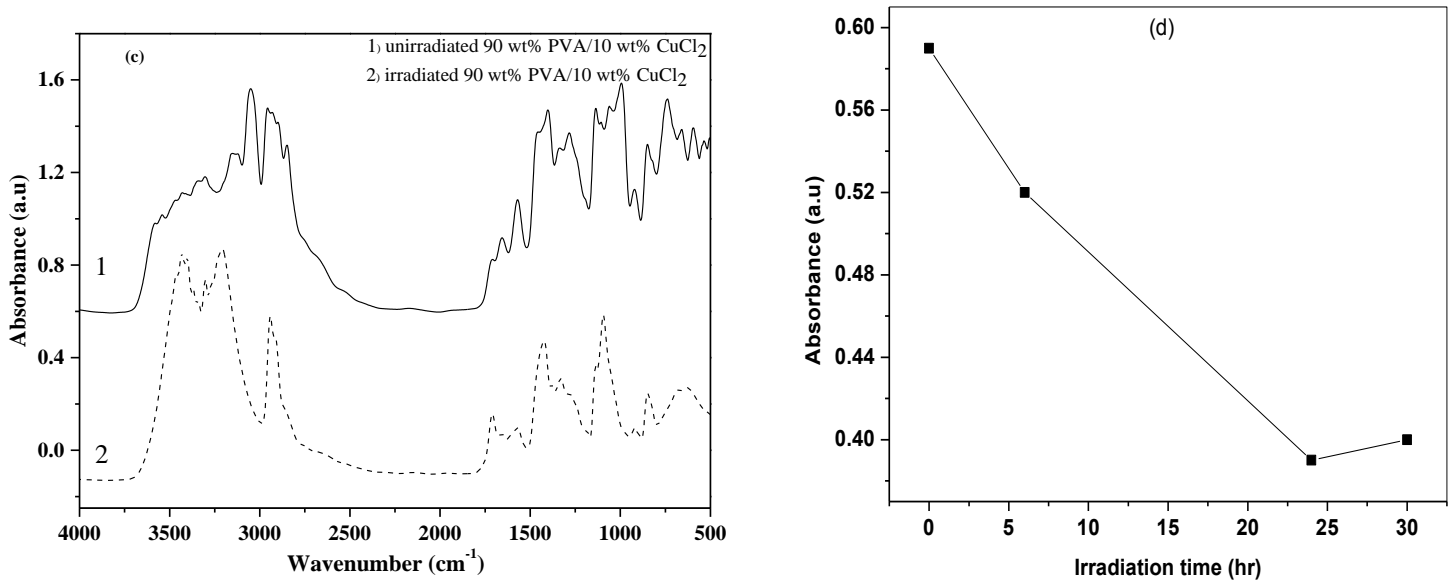

$\mathrm{PVA} / \mathrm{CuCl}_{2}$ composite sample with $\mathrm{CuCl}_{2}$ concentration of $10 \mathrm{wt} \%$ is chosen as a representative sample, to examine the effect of UV-irradiation, as observed in Fig. 4c. It is observed that, some bands such as, 3428, 3345, 2957 and $1104 \mathrm{~cm}^{-1}$ are shifted towards 3404,3342, 2943 and $1094 \mathrm{~cm}^{-1}$ and the intensity of these bands is decreased with UV irradiation, indicating to the formation of crosslinking network because of the photochemical reaction in $\mathrm{PVA} / \mathrm{CuCl}_{2}$ composites [2]. The observed shift in the absorption bands of $\mathrm{OH}$ groups is due to inter/intramolecular interactions in the composite materials. This behavior could be related to a decrease in $\mathrm{OH}$ groups of the composite. UV irradiation of $\mathrm{PVA} / \mathrm{CuCl}_{2}$ composites with a long time results in a decrease in $\mathrm{H}$ and $\mathrm{OH}$ groups, leading to the reduction of water molecules content in the materials. The reduction of water molecules from the composite materials affects the hydroxyl groups and forms a crosslinking network. Therefore, the intensity of $\mathrm{OH}$ group is decreased with increasing the irradiation time [2], as shown in Fig. $4 d$. 


\section{5: UV-Vis Spectroscopy}
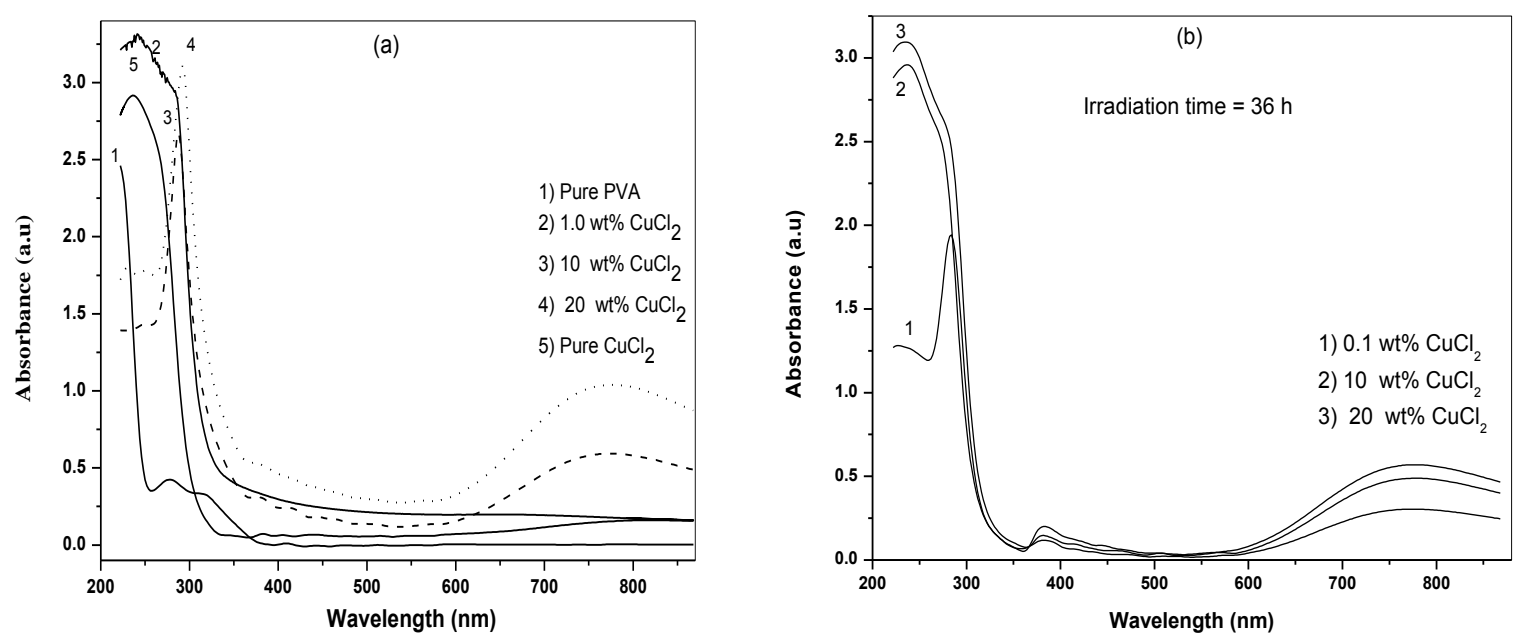

Fig. 5: UV spectrum of a) unirradiated and b) irradiated samples.

Investigation of UV region is very important to know the electronic band gap of materials. UV spectra of both pure PVA and doped PVA/CuCl 2 materials have been carried out in the range of wavelength from 200 to $850 \mathrm{~nm}$. It is observed that, PVA is characterized by two bands located at 278 and $313 \mathrm{~nm}$, as shown in Fig. 5a. No absorption bands are observed at higher wavelengths. The band at $278 \mathrm{~nm}$ could be related to the absorption of the carbonyl groups conjugated with one ethylenic group of $-\mathrm{CO}-(\mathrm{C}=\mathrm{C})-$ and $\mathrm{CO}-(\mathrm{C}=\mathrm{C}) 2-$, whereas, the band at $313 \mathrm{~nm}$ is attributed to $-\mathrm{CO}-(\mathrm{C}=\mathrm{C}) 3$-groups [17].

It is observed that, pure $\mathrm{CuCl}_{2}$ is characterized by a band at $236 \mathrm{~nm}$. On the other hand, doped samples are characterized by three bands at 249, 292 and $375 \mathrm{~nm}$. The sharp decrease in the absorption spectra of pure PVA is attributed to the optical band gap of PVA and is moved to the higher wavelength for doped samples. It is interesting to observe that, the highly doped samples with $\mathrm{CuCl}_{2}$ showed a broad absorption peak at $778 \mathrm{~nm}$. This peak is attributed to the surface plasmon resonance (SPR) of $\mathrm{CuCl}_{2}$ particles as a result of collective oscillation of free conduction electrons stimulated by the interacting electromagnetic field [18].

Fig. $5 \mathrm{~b}$ displays UV absorption spectra of irradiated doped samples. It is observed that, the intensity of the absorption is increased and the absorption peak is shifted towards higher frequency with increasing irradiation time. The absorption coefficient $(\cdot)$ plays a valuable role in determining many important parameters such as, the absorption edge, the optical energy band gap $\left(E_{g}\right)$ and Urbach energy $\left(E_{u}\right)$. The optical absorption coefficient of all samples can be calculated using the following equation [19].

$$
\alpha(v)=2.303 \frac{A}{d}
$$

Where, $A$ and $d$ are absorbance and thickness of the sample, respectively. Fig. $6(a \& c)$ displays the variation of optical absorption coefficient $(\cdot)$ against photon energy $(h \cdot)$ for all samples before and after UV irradiation. The values of absorption edge are estimated by extrapolating the linear portion of $\cdot$ versus $h$ - to zero absorption value and summarized in Table 2 .

On the other hand, the optical energy band gap $\left(E_{g}\right)$ values of the samples under investigation are calculated using the following formula [20]. 


$$
\alpha=B^{\left(h v-E_{g}\right)^{n}} / h v
$$

Where is the optical absorption coefficient, B is a constant and depends on the transition probability, $\mathrm{h}$ - is the photon energy and $\mathrm{n}$ is an index depends on the nature of the transition and is related to the distribution of density of states. For direct transitions, $n$ equals to $1 / 2$ or $3 / 2$, whereas, for indirect transition $n$ equals to 2 or 3 , depending on whether they are allowed or forbidden, respectively. Fig. $6(\mathrm{~b} \& d)$ shows $(\cdot h \cdot)^{2}$ against $\mathrm{h}$ - for all samples before and after UV irradiation. The direct optical energy band gap values are calculated estimated from the intercept of the extrapolated linear portion of $(\cdot h \cdot)^{2}$ on the photon energy axis, as shown in Fig. 6(b\&d), and listed in Table 2.
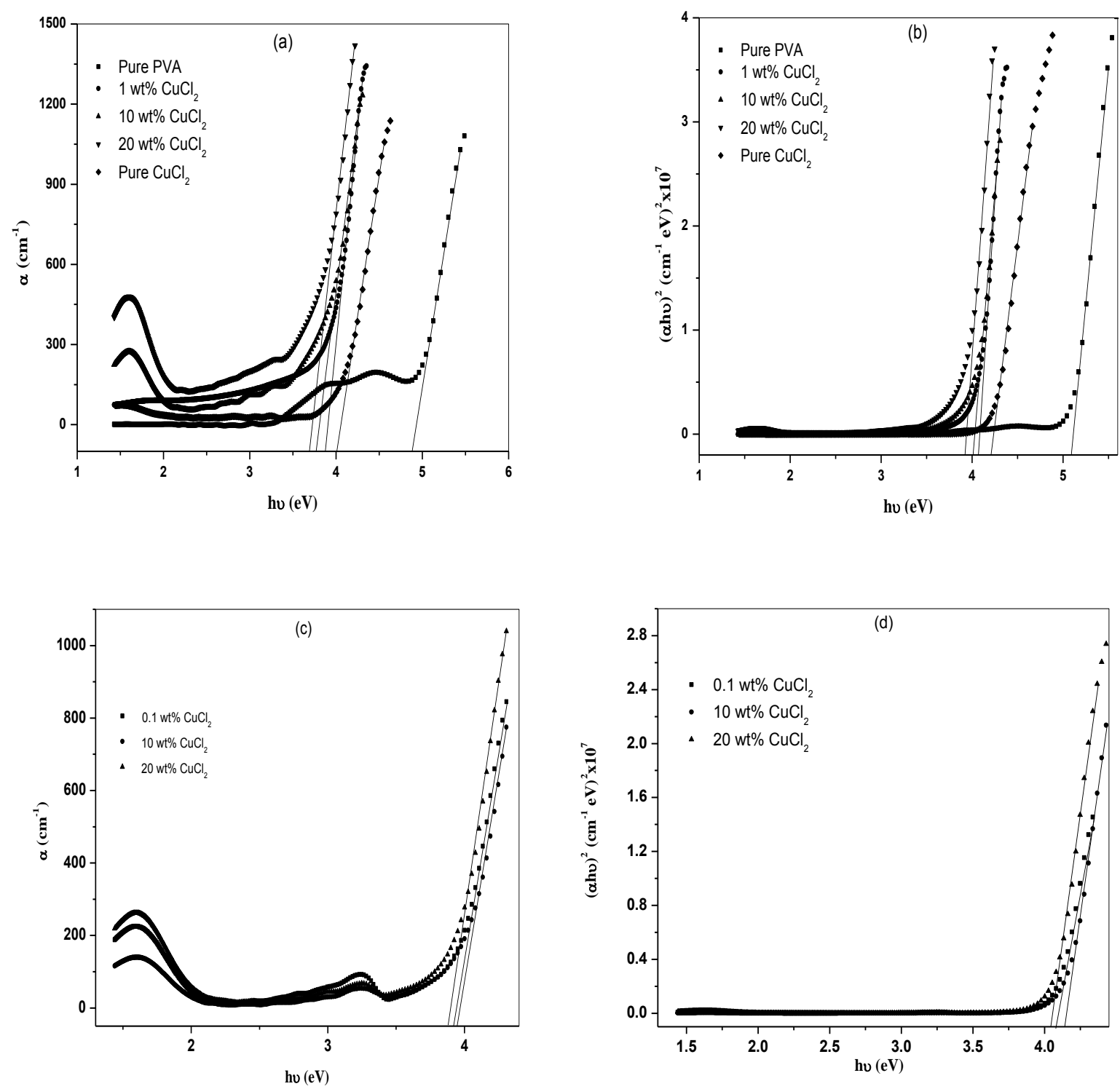

Fig. 6: a) Optical absorption coefficient $(\cdot), b)(\cdot h \cdot)^{2}$ against photon energy $(h \cdot)$ for pure PVA, pure $\mathrm{CuCl}_{2}$ and $\mathrm{PVA} / \mathrm{CuCl}_{2}$ doped samples, c) optical absorption coefficient $\left.(\cdot), \mathrm{d}\right) \cdot \cdot \mathrm{h} \cdot .^{2}$ against photon energy $(\mathrm{h} \cdot)$ for irradiated $0.1 \mathrm{wt} \%, 10 \mathrm{wt} \%$ and $20 \mathrm{wt} \% \mathrm{CuCl}_{2}$. 
Table 2: The values of absorbance edge, direct energy gap and Urbach energy.

\begin{tabular}{l|cc|cc|c}
\hline Sample & \multicolumn{2}{|c|}{ Absorbance edge (eV) } & \multicolumn{2}{|c|}{ Direct energy gap, (eV) } & Urbach energy, $\mathrm{E}_{\mathrm{u}}(\mathrm{eV})$ \\
\hline & $\begin{array}{c}\text { Before } \\
\text { irradiation }\end{array}$ & $\begin{array}{c}\text { After } \\
\text { irradiation }\end{array}$ & $\begin{array}{c}\text { Before } \\
\text { irradiatio } \\
\mathrm{n}\end{array}$ & $\begin{array}{c}\text { After } \\
\text { irradiation }\end{array}$ & \\
\hline Pure PVA & 4.88 & --- & 5.08 & --- & 0.56 \\
Pure CuCl & 3.99 & --- & 4.20 & --- & 0.52 \\
$0.1 w t \% \mathrm{CuCl}_{2}$ & --- & 3.92 & --- & 4.08 & --- \\
1 wt\% $\mathrm{CuCl}_{2}$ & 3.87 & --- & 4.06 & --- & 0.62 \\
$10 w t \% \mathrm{CuCl}_{2}$ & 3.77 & 3.95 & 4.01 & 4.14 & 0.85 \\
$20 \mathrm{wt} \% \mathrm{CuCl}_{2}$ & 3.69 & 3.88 & 3.92 & 4.04 & 0.99
\end{tabular}

The different calculated values of direct optical energy gap before and after UV irradiation indicate to the effective role of $\mathrm{CuCl}_{2}$ in improving the electronic structure of pure PVA. It is observed that, with increasing dopant concentration, the direct optical energy gap is decreased. This behavior can be explained based on the $\mathrm{CuCl}_{2}$ particles form charge transfer complexes in PVA matrix [21]. Hence, the electrical conductivity will increase by providing additional charges, resulting in a lowering in the optical energy gap.

As already well known, the optical absorption coefficient $(\cdot)$ depends on the photon energy $(h \cdot)$ in non-crystalline materials. The relation between absorption coefficient and photon energy $(h \cdot)$ near the optical band gap is known as Urbach formula, which can be expressed as follows [22]:

$$
\alpha=\alpha_{o} \exp \left(h v / E_{U}\right)
$$

Where $\cdots \cdot, h \cdot$ and $\mathrm{E}_{\mathrm{u}}$ are defined as the absorption coefficient, constant, incident photon energy and Urbach energy, respectively.

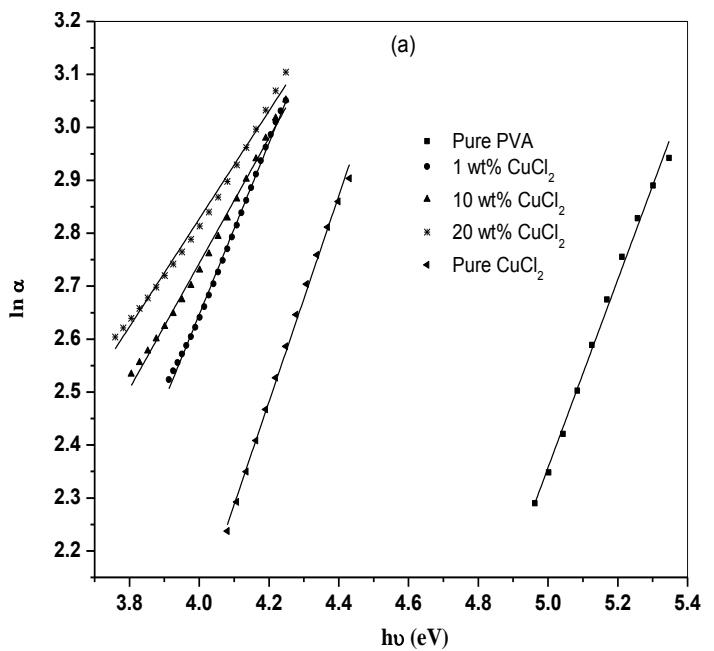

Fig.7: Variation of $\mathrm{In} \cdot$ against the photon energy $(\mathrm{h} \cdot)$ of $\mathrm{PVA} / \mathrm{CuCl}_{2}$ composite films. 
The values of Urbach energy of the localized states in the optical energy gap of $\mathrm{PVA} / \mathrm{CuCl}_{2}$ composites are estimated by taking the reciprocal of the slope of plotting $\ln \cdot$ against $h \cdot$, as shown in Fig. 7 . The values of Urbach energy are summarized in Table 2. It is found that, values of $E_{u}$ are changed from 0.56 to $0.99 \mathrm{eV}$ with increasing the content of $\mathrm{CuCl}_{2}$, indicating to an increase in the defects in the polymer matrix will be occurred. These defects can introduce localized states at or near the conduction band resulting in an increase in the values of Urbach energy [23].

\section{Conclusion}

Atomic force microscope (AFM) and scanning electron microscope (SEM) have been used to investigate the effect of $\mathrm{CuCl}_{2}$ on the structure of PVA. XRD revealed that, the crystallinity of PVA is increased with increasing $\mathrm{CuCl}_{2}$ ratio. In addition, FTIR spectra showed that, some absorbance bands such as bands of $\mathrm{C}=\mathrm{O}$ and of $\mathrm{OH}$ groups have been affected due to $\mathrm{CuCl}_{2}$ ratio and UV irradiation. The effect of $\mathrm{CuCl}_{2}$ ratio and UV irradiation on UV spectra of all samples has been examined in the range from 200 to $800 \mathrm{~nm}$. It is observed that, pure PVA is characterized by two absorbance bands at 278 and $313 \mathrm{~nm}$. On the other hand, a broad absorption peak at $778 \mathrm{~nm}$ is observed for both highly doped samples and irradiated samples. This peak is attributed to the surface plasmon resonance (SPR) of $\mathrm{CuCl}_{2}$ particles. The values of absorbance edge, direct energy gap and Urbach energy of all samples have been calculated. It is found that, with increasing $\mathrm{CuCl}_{2}$ ratio, the direct energy gap is decreased, whereas, Urbach energy is increased.

\section{References}

[1] Kowalonek J., Kaczmarek H. and Dabrowaska A., Appl. Surf. Sci., 257, (2010) 325-331.

[2] Sheela T., Bhajantri R. F., Ravindrachary V., Rathord S. G., Pujari P. K., Poojary B. and Somashekar R., Rad. Phys. \& Chem. 103, (2014) 45-52.

[3] Devi C. U., Sharma A.K. and Rao V.V.R.N., Material Lett. 56, (2002) 167-174.

[4] Bhargav P. B., Mohan V. M., Sharma A. K. and Rao V. V. R. N., Ionics. 13, (2007) 173-178.

[5] Asogwa P., Ezugwu S. and Ezema F., Superficies y Vacio. 23, (2010) 18-22.

[6] Vandervorst P., Lei C., Lin Y., Dupont O., Dalton A., Sun Y. and Keddie J., Prog. Org. Coat. 153, (2003) 163205.

[7] Fahmy T., Intern. J. Polymeric Mater., 50, (2001) 109-127.

[8] Ghani A. and Young H., J. Phys. Sci., 21, (2010) 81-97.

[9] Mohammed R. and Gadou A., Egypt. J. Solid 23, (2000) 277-286.

[10] Yamamoto S., Tsujii Y. and Fukuda T., Polymer, 42, (2001) 2007-2013.

[11] Lee M. Y., Kim S. H., Ganapathy H. S., Kim S. W. and Lim K. T., Ultramicroscopy, 108, (2008) 1210-1214.

[12] Jin L. and Bai R. B., Langmuir, 18, (2002) 9765-9770.

[13] Mooney R. C. L., J. Am Chem., 63, (1941) 2828-2832.

[14] Kihira Y. and Yamamura H., J. Polym. Sci. B 24, (1986) 867-876.

[15] A. Boultif, D. Louer, J. Appl. Cryst., 37, (2004) 724-731.

[16] Abdel-Hakeem N., Polym. Deg. \& Stab., 36, (1992) 275-279.

[17] Moroso D., Cella D. A. and Peccatori E., Chim. Ind. (Milan) 25, (1987) 1897. 
[18] Aziz S.B., Abidin, Z.H.Z. and Arof A.K., express, Polym. Lett. 4, (2010) 300-310.

[19] Ballato J., Foulger S. and Smith D. W., J. Opt. Soc. Amer., B20, (2003) 18381843.

[20] Tauc, T., "Amorphous and liquid semiconductors", (NY, Plenum), p. 159 (1974).

[21] Raja V, Sarma A. K. and Rao, V. V. R. N., Materials Lett., 57(30), (2003) 4678-4683.

[22] Urbach F., Phys. Rev. 92, (1953) 1324-1324.

[23] Muiva C. M., Sathiaraj, T. S. and Mwabora, J. M., Eur. Phys. J. Appl. Phys. 59 (2012) 10301. 